\title{
A PERSPECTIVE-BASED ACCOUNT OF THE IMPERFECTIVE PARADOX
}

\author{
Gaetano Fiorin (G.Fiorin@uu.nl) \\ Denis Delfitto (denis.delfitto@univr.it) ${ }^{1}$
}

Kazanina and Phillips (Cognition (2007) 105:65-102) distinguish two accounts of the progressive and imperfective: the 'perspective-based' approach and the 'event-based' approach. The event-based approach maintains that imperfective and perfective refer to different classes of events. The perspective-based approach maintains that imperfective and perfective encode different perspectives towards otherwise ontologically and metaphysically equivalent events. The event-based approach is preferable over the perspective-based approach because it accounts for the imperfective paradox, that is, for the fact that imperfective and progressive morphology make it possible to use a telic predicate like 'drive to Bordeaux', which is defined by its endpoint, reaching Bordeaux, to describe an event that is only a partial event of driving to Bordeaux. The perspective-based approach, on the other hand, is supported by experimental findings on the acquisition of the meaning of the imperfective. In this article, we propose an alternative approach to the progressive/imperfective that can account both for the imperfective paradox and the experimental findings. The proposal is based on two main ideas: (i) as in the perspectivebased approach, the role of the progressive and imperfective is to present events from an internal perspective, whereas the role of the perfective is to present events from an external perspective; (ii) progressive and imperfective sentences involve quantification over inertia worlds, as in the modal variant of the event-based approach; however, the modal import of progressive sentences is not brought about by the progressive operator, but is a property of telic predicates themselves.

\section{INTRODUCTION}

Kazanina and Phillips (2007) distinguish two types of account of the meaning of progressive and imperfective morphology: the 'perspective-based' approach and the 'event-based' approach. According to the perspective-based approach, the role of progressive and imperfective is to present an eventuality from an internal perspective, whereas, according to the event-based approach, progressive and imperfective are used to refer to ongoing eventualities.

The event-based approach is preferable over the perspective-based approach because it accounts for the so-called imperfective paradox, that is, for the fact that progressive and imperfective morphology allow suspending the completion entailment associated with telic predicates. However, Kazanina and Phillips (2007) report the results of an experiment aimed at testing the interpretation of the imperfective in children. As the authors summarize, the results show that 'children are only willing to accept an imperfective predicate as a description of a past incomplete event when the sentence contains an explicit temporal modifier that highlights a time interval that ends before the failure point of the event' (pp. 65-

\footnotetext{
${ }^{1}$ We thank Nina Kazanina, Jacques Moeschler, Paola Monachesi, and Elena Pagliarini for valuable comments and suggestions on preceding versions of this paper. Needless to say, all errors are ours.
} 
66). The findings reported by Kazanina and Phillips support the perspective-based approach and contrast with the predictions of the event-based approach.

In this article, we propose an alternative approach to the progressive/imperfective, extending a proposal by Bennett (1977). The theory aims at accounting for both the imperfective paradox and the experimental results of Kazanina and Phillips. The proposal is based on two main ideas: (i) as in the perspective-based approach, the role of the progressive is to present events from an internal perspective, whereas the role of the perfective is to present events from an external perspective; (ii) progressive sentences involve quantification over inertia worlds, as in the modal variant of the event-based approach; however, the modal import of progressive sentences is not brought about by the progressive operator, but is a property of telic predicates themselves.

The article is organized as follows. In section 1, we introduce the so-called 'imperfective paradox'. In section 2, we introduce the main features of the perspective-based approach and, in section 3, we discuss why it is empirically unsatisfactory. In section 4, we briefly discuss the event-based approach, in its extensional and modal variants. Section 5 offers an overview of the experimental results of Kazanina and Phillips. In section 6, we introduce our proposal and discuss how it accounts for both the imperfective paradox and the results reported by Kazanina and Phillips. Finally, in section 7, we show how the proposal can account for the different entailment properties of two classes of ditransitive verbs.

\section{THE IMPERFECTIVE PARADOX}

The fact that (1) and (2) do not entail (3) is known as the 'imperfective paradox' (Dowty, 1972).

John is driving to Bordeaux.

(2) John was driving to Bordeaux.

(3) John drove to Bordeaux.

The paradox corresponds to the fact that imperfective and progressive ${ }^{2}$ morphology make it possible to use a telic predicate like 'drive to Bordeaux', which is defined by its endpoint, reaching Bordeaux, to describe an event that is only a partial event of John driving to Bordeaux. In fact, sentence (4) can be uttered truthfully in a scenario in which John's car broke in Toulouse, and therefore John never arrived to Bordeaux. That is, the progressive allows suspending the culmination entailment built in the meaning of telic predicates.

When his car broke, John was driving to Bordeaux.

\section{THE PERSPECTIVE-BASED APPROACH}

One approach to the meaning of the progressive/imperfective assumes that the role of the progressive/imperfective is to present the eventuality denoted by the verb phrase from an internal perspective (Bennett and Partee, 1972; Kamp \& Reyle, 1993; Klein, 1994; 1995; Reichenbach, 1947; Smith, 1991). I will refer to this approach as the 'perspective-based

\footnotetext{
${ }^{2}$ Throughout the article, we will regard imperfective and progressive as a uniform category, since what we are interested in is the fact that they are both sources of the imperfective paradox. This is indeed an oversimplification that leaves many important issues aside (see in particular the discussion in Delfitto, 2002, 2004).
} 


\section{GAETANO FIORIN AND DENIS DELFITTO}

approach' (borrowing the label from Kazanina and Phillips, 2007). The imperfective paradox is then accounted, on an intuitive level, as follows: since the role of the progressive is to present an eventuality from an 'internal point of view', the eventuality is perceived as ongoing.

This approach capitalizes on the idea that tensed sentences are evaluated relatively to a reference time (Partee, 1973; Reichenbach, 1947). Consider first the simple-past sentence in (5): the sentence is true iff an event of John driving to Bordeaux took place yesterday afternoon. More precisely, the sentence is true iff there is an event ${ }^{3}$ of John driving to Bordeaux whose temporal extension, call it the event time, is included in the time extension corresponding to yesterday afternoon, call this interval of time the reference time.

Yesterday afternoon, John drove to Bordeaux

The role of the progressive/imperfective is to encode the opposite relation between event time and reference time. Sentence (6), for example, is true iff there is an event of John driving to Bordeaux and the reference time, yesterday afternoon, is included within the event time.

$$
\text { Yesterday afternoon, John was driving to Bordeaux }
$$

Fig. $1 \mathrm{a}$ and $1 \mathrm{~b}$ give a graphic representation of the relation between reference time and event time in, respectively, simple-past and past progressive sentences.

Fig. 1a

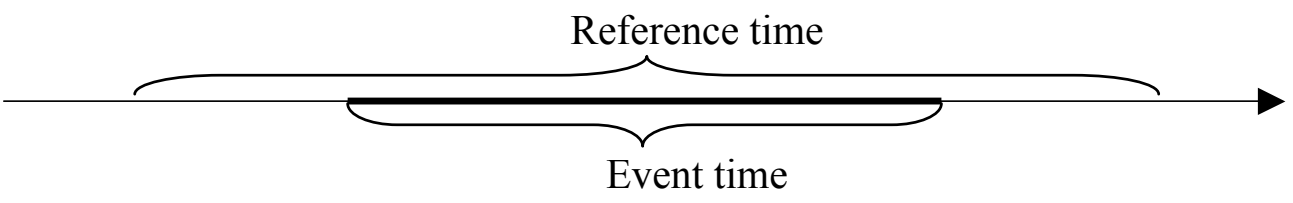

Fig. 1b

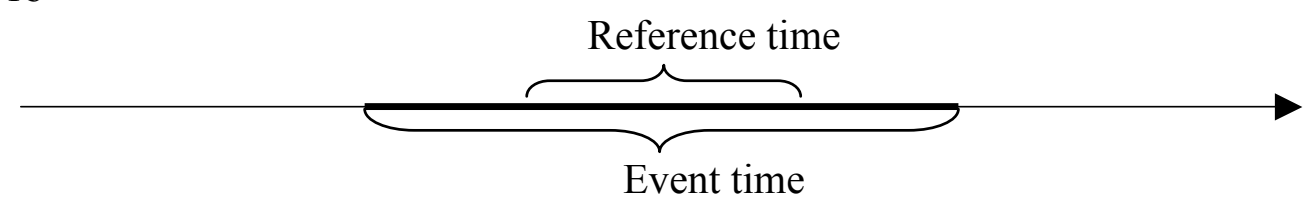

INADEQUACY OF THE PERSPECTIVE-BASED APPROACH

The perspective-based approach has been challenged and eventually dismissed because unable to provide an explanatorily adequate account of the imperfective paradox. To see why, consider an actual formal implementation of the perspective-based account, as presented in (7). In (7), $P R O G$ is the progressive/imperfective operator, which applies to a property of events $P$ and a reference time $i$ (we are provisionally ignoring tense, since it is not crucial for the point we want to make).

(7) $\quad[\mathrm{PROG}(\mathrm{P}, \mathrm{i})]$ is true iff there is an event $e$ of $P$ and $i$ is included in the temporal extension of $e$.

\footnotetext{
${ }^{3}$ Throughout the article, we will use the term event in a broad sense, that is, to refer to the class of objects denoted by verb phrases. In this respect, our use of the term event corresponds to Bach's (1986) use of the term eventuality.
} 
To see an example, according to (7), (1) is true, relatively to the reference time $i$ corresponding to yesterday afternoon, iff there is an event $e$ of John driving to Bordeaux and $i$ is included in the temporal extension of $e$.

It is easy to see now that, if we maintain that the extension of the bare (uninflected) telic predicate John drive to Bordeaux is the set of events of John driving that end in Bordeaux $^{4}$, (7) fails to account for the imperfective paradox. According to (7), (1) entails the existence of an event of John driving to Bordeaux. However, the imperfective-paradox tells us that the sentence can be true in a state of affairs in which John never reached Bordeaux, and, therefore, no event of that qualifies as an event of John driving to Bordeaux took place.

\section{THE EVENT-BASED APPROACH}

Because of the criticism reviewed in the preceding section, alternative accounts of the progressive/imperfective have been developed, which are based on the general intuition that the progressive/imperfective encodes reference to 'ongoing events' or 'events in progress'. We will refer to this type of approach as the 'event-based approach' (again, we are borrowing the label from Kazanina and Phillips, 2007).

The event-based approach comes in two main variants: an extensional version and a modal version. ${ }^{5}$ The extensional version, in the form presented by Parsons (1990), is developed on the assumption that predicate denotations, which in Parsons' semantics are sets of events, include both complete and incomplete events. Parsons observes that the world contains a number of incomplete objects, such as incomplete houses and incomplete circles, and that language users are quite liberal in referring to these objects as houses and circles. In a similar vein, he proposes that the world also contains incomplete events of building a house or drawing a circle and language users are liberal enough to refer to them as events of building a house and drawing a circle. The progressive operator, according to Parsons, restricts the denotation of the bare predicate to incomplete events. Accordingly, the truth conditions of PROG, as applied to a property of events $P$, are as in (8), where the predicate Hold is true only of those events that are incomplete.

$[\mathrm{PROG}(\mathrm{P})]$ is true iff there is an event $e$ of $P$ and Hold $(e)$.

Parsons approach successfully deals with the imperfective paradox, because incomplete events are, by definition, events that do not reach their culmination.

The modal version of the event-based approach assumes that the progressive operator has a modal import. This line of analysis has been initiated by Dowty (Dowty, 1977; 1979) and further elaborated in subsequent works by, among others, Asher, Landman and Portner (Asher 1992, Landman, 1992; Portner, 1998). Here, I am taking Portner's theory as representative of the modal approach, given that it subsumes the most relevant insights of both Dowty's and Landman's proposals and has a large empirical coverage. According to Portner (1998), the truth-conditions of PROG, as applied to a property of events $P$, are as in (9).

\footnotetext{
${ }^{4}$ Of course, one may question the assumption that the predicate John drive to Bordeaux denotes only those events that are complete events of John driving to Bordeaux. This is in fact what Parsons (1990) does. Parsons theory is discussed in section 4.

${ }^{5}$ See Zucchi (1999) for a detailed comparison of the extensional and modal versions of the event-based approach.
} 


\section{GAETANO FIORIN AND DENIS DELFITTO}

(9) $\quad[\mathrm{PROG}(\mathrm{P})]$ is true at a world $w$ iff there is an event $e$ in $w$ such that, for every

inertia world $w^{\prime}$ accessible from $w$, there is an event $e^{\prime}$ such that $e$ is a subpart of $e^{\prime}$ and $e^{\prime}$ is $P$ in $w^{\prime}$.

Portner follows Dowty's original insight in assuming that the progressive operator has a modal import and encodes universal quantification over a restricted set of possible worlds. He follows Kratzer (1991) in identifying the relevant set of possible worlds on the basis of two contextually defined parameters: a modal base and an ordering source. The modal base is a circumstantial modal base, corresponding to the set of propositions relevant to whether the event denoted by the bare predicate is completed. The ordering source is an inertial ordering source, corresponding to the set of propositions that express that the event is not interrupted. In conclusion, the set of inertia worlds for a given event $e$ is the set of worlds, defined by the circumstantial modal base and the inertial ordering source, in which nothing interrupts $e$ and $e$ reaches its natural culmination.

Also the modal approach successfully deals with the imperfective paradox. According to (9), a progressive sentence of the form $[\mathrm{PROG}(\mathrm{P})]$ is true as long as there is an event $e$ of $P$ in every inertia world, that is, in every possible world in which the event $e$ can proceed uninterrupted. Crucially, (9) does not entail that an event of $P$ took place in the actual world, since the actual world need not be an inertia world. All that has to take place in the actual world is an ongoing event of $P$, that is, an event that, in every inertia worlds, is a subpart of an event of $P$.

\section{EXPERIMENTAL EVIDENCE IN FAVOR OF THE PERSPECTIVE-BASED APPROACH}

Despite the arguments reviewed in the previous sections, there is experimental evidence that speaks in favor of the perspective-based approach and against the event-based approach.

Kazanina and Phillips (2007), henceforth KP, present a battery of language acquisition experiments aimed at providing empirical evidence in favor or against the two approaches discussed above. KP's work is grounded on the following considerations:

Perspective-based approaches stress the importance of appropriately locating a temporal perspective on an event in accounting for the absence of completion entailments with the imperfective. Under these approaches we may suppose that children's success in using the imperfective with an incomplete event should depend on their ability to choose an appropriate perspective from which to evaluate the event. For example, we may assume that cases like (2a) [= While Katy talked on the phone, John was building a toy house] in which the perspective on the event is provided by an explicit temporal modifier-the while-clauseshould be easier for the child to interpret appropriately, since the child does not need to choose the perspective for himself. Under event-based approaches, on the other hand, children's ability to relate imperfectives to incomplete events should not be affected by the presence or absence of a temporal modifier phrase that provides an explicit insider perspective on the event. This is because such theories [...] do not rely upon the notion of a temporal perspective. Instead, event-based approaches might predict that children should encounter difficulty if they cannot successfully recognize that an unfinished or partial event is an instance of the relevant complete event-type. Under intensional approaches, difficulty may arise if children have difficulty in computing plausible continuations of events. This difficulty is especially likely in situations where the completion of the event is counterfactual. Under extensional approaches, difficulty may arise if the child fails to recognize an incomplete event as belonging to the denotation of the corresponding predicate (KP, p. 71). 
To test these predictions, KP administered a battery of four experiments to a group of children aged between 3 and 6 years, all monolingual native speakers of Russian. ${ }^{6}$ In what follows, we will briefly review Experiments 1, 3, and 4 and their main results. We will not discuss the results of Experiment 2, as they are not directly relevant for the present discussion. ${ }^{7}$

\subsection{Experiment 1}

In Experiment 1 children were presented a set of stories following the same pattern (adapted from Wagner, 2001). In the story,

[...] a toy animal went down a road with three landmarks: a flowerbed, a castle and a tree. A given action, that could be performed to completion at each location, was performed completely at one location only, incompletely at one other location, and not at all at a third location. [...] At the incomplete location, the reason why the main event did not reach completion was always an interruption: the agent was distracted from the main event and could not finish it because of an intervening event $[\ldots]$ (KP, p. 75).

At the end of each story, the experimenter asked the child a series of questions, which included a perfective (e.g. 10) and an imperfective (e.g. 11) question, separated by a control question (the order of the perfective and imperfective question was randomized across trials).

$\begin{array}{lll}\text { Gde obezjyanka } & \text { sobrala } & \text { gnomika? } \\ \text { where monkey } & \text { assemble.Past.Perf. } & \text { smurf } \\ \text { 'Where did the monkey build a smurf?' } & \end{array}$
Gde obezjyanka sobirala gnomika? where monkey assemble.Past.Imp. smurf 'Where was the monkey building a smurf?'

The results of Experiment 1 are reported in Table 1.

Table 1

Overall accuracy in children's performance with perfective and imperfective queries in Experiment 1

(23 children tested)

\begin{tabular}{ll}
\hline Query & $\%$ correct \\
\hline Perfective & $95 \%$ \\
Imperfective & $39 \%$ \\
\hline
\end{tabular}

The difference between perfective and imperfective questions is statistically significant and is not affected by the order in which the questions were presented (see KP, p. 77). Moreover, children's scores were compared with those of a group of 10 adult subjects (native speakers of Russian), who consistently provided correct answers to both perfective and imperfective questions. Notably, the 'overwhelming majority of incorrect responses to imperfective queries were due to the same error, namely the child's failure to associate the imperfective with an incomplete event' (KP, p. 77).

\footnotetext{
${ }^{6}$ See KP, pp. 71-72, for a discussion of the motivations for choosing Russian as the test-language.

${ }^{7}$ Experiment 2 replicates the results of Experiment 1 using a different class of telic predicates.
} 


\section{GAETANO FIORIN AND DENIS DELFITTO}

\subsection{Experiment 3}

In Experiment 3, a truth-value judgment task, children were asked to judge imperfective and perfective sentences such as (12) and (13).

Poka malchik polival cvety, devochkla vytirala stol

while boy water.Past.Imp. flowersgirl clean.Past.Imp.table

'While the boy was watering the flowers, the girl was cleaning the table.'

Poka malchik polival cvety, devochkla vyterla stol
while boy water.Past.Imp. flowersgirl clean.Past.Imp.table
'While the boy was watering the flowers, the girl cleaned the table.'

Notice that these sentences contain a while-clause that explicitly provides an explicit temporal interval for the evaluation of the predicate in the main clause.

Subjects were asked to evaluate the sentences against a situation in which

[...] a boy starts watering some flowers and shortly thereafter a girl starts cleaning a table. After a while, the boy finishes watering the flowers and starts riding his bike. While he is riding the bike, the girl successfully finishes cleaning the table. In order to evaluate the truth of [(12)] or [(13)] against this situation, the speaker must determine whether the proposition expressed by the main clause holds at the interval delimited by the temporal modifier [...]. For an adult speaker of Russian [(12)] is true because the truth conditions of the imperfective main clause are satisfied during the evaluation interval: informally, there was a table-cleaning event that was ongoing during the interval delimited by the flower-watering event. On the other hand, [(13)] is false, since the truth conditions of the perfective predicate devochka vyterla stol 'the girl cleaned (all of) the table' are not satisfied during the interval specified by the temporal modifier: the table was not cleaned completely while the boy was watering the flowers. Importantly, it is precisely because speakers evaluate the main clause perfective predicate at the interval defined by the while-clause that $[(13)]$ is false; the proposition expressed by the main clause is true at a larger interval that includes the entire table-cleaning event (KP, p. 84).

The results of Experiment 3 are reported in Table 2 and show that (a) children used the correct temporal interval for the evaluation of perfective sentences and (b) they are able to associate imperfective sentences with incomplete events.

Table 2

Children's performance on perfective and imperfective queries in Experiment 3 (30 children tested)

\begin{tabular}{ll}
\hline Query & $\%$ correct \\
\hline Perfective & $91 \%$ \\
Imperfective & $89 \%$ \\
\hline
\end{tabular}

However, as KP notice, the improved performance of children may have been due to either of the two features of Experiment 3. It may reflect the fact that a temporal perspective is provided explicitly by the while-clause, but it may also reflect the fact that the event referred to by the imperfective sentence is a portion of an event that does reach its culmination in the given scenario. Experiment 4 is designed to tease these two alternatives apart. 


\subsection{Experiment 4}

Experiment 4 differs from Experiment 3 only in that the event referred to by the target sentences does not reach its culmination:

As in Experiment 3, the table-cleaning event carried out by the girl overlapped with the boy's watering of the flowers, and later on with his biking. The difference is that eventually the girl failed to clean the table completely (because she ran out of cleaning solution). This change in the outcome of the table-cleaning event does not affect the truth-value of [(12)] and [(13)] for Russian-speaking adults: the imperfective [(12)] is true and the perfective [(13)] is false in both situations [...]. This should not be surprising, since the truth-value of the sentence is obtained by evaluating the main clause at the interval defined by the while-clause, during which the two situations are identical. However, in Experiment 3 the main predicate in [(12)] referred to a non-counterfactual event (a subpart of a completed past event), whereas in Experiment 4 it picked out a counterfactual event (a subpart of a permanently incomplete past event) (KP, p. 88).

The results are reported in Table 3 and show that children (a) correctly rejected the perfective sentences with incomplete events and (b) correctly accepted the imperfective sentences as referring to subparts of incomplete events.

Table 3

Children's performance on perfective and imperfective queries in Experiment 4 (20 children tested)

\begin{tabular}{ll}
\hline Query & $\%$ correct \\
\hline Perfective & $90 \%$ \\
Imperfective & $84 \%$ \\
\hline
\end{tabular}

\subsection{Summary}

To summarize, KP found that children have a significant tendency to associate imperfective sentences with complete events and to refuse to associate them with incomplete events, as they did not know the completion entailment suspension triggered by the imperfective (Experiment 1). However, they also found that children correctly allow imperfective sentences to refer to incomplete events when imperfective sentences are preceded by a whileclause that provides an explicit temporal interval for the evaluation of the main clause (Experiment 4). As the authors put it, 'children are only willing to accept an imperfective predicate as a description of a past incomplete event when the sentence contains an explicit temporal modifier that highlights a time interval that ends before the failure point of the event' (KP, pp. 65-66). These results fulfill the predictions made by the perspective-based approach, and contrast with the predictions made by the event-based approach.

\section{A NOVEL PERSPECTIVE-BASED ACCOUNT OF THE IMPERFECTIVE PARADOX}

Two conclusions can be drawn from the discussion in the previous sections: (a) the eventbased approach is superior to the perspective-based approach in that it provides a formal account of the imperfective paradox; (b) the perspective-based approach is superior to the event-based approach in that it is supported by the experimental findings reported by KP. How can the important insights of these two approaches be reconciled? The next sections of the present article offer an attempt at meeting this challenge. 


\section{GAETANO FIORIN AND DENIS DELFITTO}

The theory we are going to propose is based on the following assumptions: (i) following the perspective-based approach, we maintain that the role of the progressive/imperfective is to present events from an internal perspective, whereas the role of the perfective is to present events from an external perspective; (ii) following the modal variant of the event-based approach, we maintain that progressive/imperfective sentences involve quantification over inertia worlds; however, we propose two modifications to this insight. Firstly, following and extending an idea by Bennett (1977), we propose that the modal import of progressive/imperfective sentences is not brought about by the progressive operator, but is a property of telic predicates themselves; secondly, following Ferreira (2005), we propose that the relevant set of inertia worlds is defined not only on the basis of a world of evaluation, a modal base, and an ordering source, as in Portner (1998), but also on the basis of a time parameter corresponding to the reference time.

We will show that the theory can account both for the imperfective paradox and for the language acquisition findings reported by KP.

Before presenting the theory, we will introduce some preliminary assumptions about time and events and the syntax and semantics of tense and aspect.

\subsection{Time and events}

Let the notion of moment of time $t$ be a primitive notion. Let $T$ be the set of moments of time, $\leq$ the dense linear ordering of $T$, and $\subseteq$ the inclusion relation. Consider the following definitions (substantially taken from Bennett and Partee, 1972):

(14) a. Interval of time:

$i$ is an interval of time iff $i \subseteq T$ and for every moment $t^{\prime}, t^{\prime \prime}, t^{\prime \prime \prime}$ such that $t^{\prime} \leq t^{\prime \prime} \leq t^{\prime \prime \prime}$, if $t^{\prime} \in i$ and $t^{\prime \prime \prime} \in i$, then $t^{\prime \prime} \in i$.

b. Subinterval relation:

$i$ is a subinterval of $j$ iff both $i$ and $j$ are intervals and $i \subseteq j$.

c. Initial boundary:

$t$ is the initial boundary of $i$ iff $t \subseteq i$ and there is no $t^{\prime}$ such that $t^{\prime} \subseteq i \quad$ and $t^{\prime} \leq t$.

d. Final boundary: $t^{\prime}$

$t$ is the final boundary of $i$ iff $t \subseteq i$ and there is no $t^{\prime}$ such that $t^{\prime} \subseteq i$ and $\quad t \leq$

e. $\quad$ Precedence $<$ :

$i$ precedes $j$ iff the final boundary of $i \leq$ the initial boundary of $j$.

f. Overlap $\cap$ :

$i$ overlaps with $j$ iff there is at least one $t$ such that $t \subseteq i$ and $t \subseteq j$.

We introduce a further definition for immediate precedence:

g. $\quad$ Immediate precedence $<_{\mathrm{I}}$ :

$i$ immediately precedes $j$ iff $i<j$ and there is no $t$ such that the final boundary of $i \leq t$ and $t \leq$ the initial boundary of $j$.

Finally, $\tau$ is a homomorphism between the domain of events and the domain of times such that for any events $e$ and $e^{\prime}, \tau\left(e \oplus e^{\prime}\right)=\tau(e) \oplus \tau\left(e^{\prime}\right)$ (Krifka, 1988); accordingly, $\tau(e)$ is the temporal extension of $e$. 


\subsection{Syntax and semantics of tense and aspect}

The theory we want to propose is a version of the perspective-based approach that integrates some insights from the event-based approach. In order to have a suitable framework in which the proposal can be grounded, in this section we lay down a simple compositional implementation of the perspective-based approach.

Following Ramchand (2004), we assume the clausal structure in (15), where Tense and Aspect are two independent heads. Accordingly, the simple-past sentence in (16a) corresponds to the structure in (16b), where Aspect hosts a perfective operator PERF and Tense hosts a past tense operator PAST. (17a) differs from (16a) in that Aspect hosts a progressive operator PROG.

$$
\text { [ [TenseP Tense [AspP Asp [vp ...]]] }
$$

(16) a. John drove to Bordeaux

b. $\quad[$ [TenseP PAST [AspP PERF [vP John drive to Bordeaux $]]]$

(17) a. John was driving to Bordeaux

b. [ [TenseP PAST [AspP PROG [vp John drive to Bordeaux $]]$

At the level of interpretation, vPs denote sets of events. For example, ${ }_{v P}$ John drive to Bordeaux] denotes the set of events of John driving to Bordeaux, as represented in (18) (where $J$ and $B$ are constants for, respectively, John and Bordeaux).

$[[$ John drive to Bordeaux $]]=\lambda \mathrm{e} . \operatorname{Drive}(\mathrm{j}, \mathrm{b}, \mathrm{e})^{8}$

Aspectual operators denote functions from sets of events into sets of time intervals. The perfective operator PERF turns the set of events denoted by the vP into the set of intervals of time that include the event time:

$$
[[\mathrm{PERF}]]=\lambda \mathrm{P} . \lambda \mathrm{i} . \exists \mathrm{e} . \tau(\mathrm{e}) \subseteq \mathrm{i} \wedge \mathrm{P}(\mathrm{e})
$$

The progressive operator PROG turns the set of events denoted by the vP into the set of intervals of time that are included within the event time:

$$
[[\mathrm{PROG}]]=\lambda \mathrm{P} . \lambda \mathrm{i} . \exists \mathrm{e} . \mathrm{i} \subseteq \tau(\mathrm{e}) \wedge \mathrm{P}(\mathrm{e})
$$

Following Partee (1973), we maintain that Tense hosts a pronoun referring to a salient interval of time, i.e. a reference time. The distinction between past and present tense is encoded as a presupposition restricting the reference of the pronoun to those intervals of time that either precede the utterance time, as in the case of Past, or overlap with the utterance time, as in the case of Present. This is given in (21) and (22), where $u$ refers to the utterance time.

(21) $[[\mathrm{PAST}]]^{\mathrm{u}}=$ pro $_{\mathrm{i}}$, provided pro $_{\mathrm{i}}<\mathrm{u}$, undefined otherwise.

$$
[[\text { PRES }]]^{\mathrm{u}}=\text { pro }_{\mathrm{i}}, \text { provided }_{\text {pro }_{\mathrm{i}}} \cap \mathrm{u} \text {, u.o. }
$$

\footnotetext{
${ }^{8}$ The only reason why we are adopting formulas such as (18), instead of neo-davidsonian formulas such as $\lambda e$. Drive (e) $\wedge$ Agent $(e)=j \wedge$ Goal $(e)=b$ (as proposed by Parsons, 1990), is simplicity.
} 


\section{GAETANO FIORIN AND DENIS DELFITTO}

Finally, consider the denotations predicted for the structures (16b) and (17b):

$$
\begin{aligned}
& \text { [[ [TenseP PAST [AspP PERF [vp John drive to Bordeaux]]] ] }]^{\mathrm{u}}= \\
& =\exists \text { e. } \tau(\mathrm{e}) \subseteq \operatorname{pro}_{\mathrm{i}} \wedge \text { Drive }(\mathrm{j}, \mathrm{b}, \mathrm{e}), \text { provided }_{\text {pro }_{\mathrm{i}}}<\mathrm{u} \text {, u.o. } \\
& \text { [[ [TenseP PAST [AspP PROG [vP John drive to Bordeaux }]]]]]^{\mathrm{u}}= \\
& =\exists \text { e. } \text { pro }_{\mathrm{i}} \subseteq \tau(\mathrm{e}) \wedge \text { Drive }(\mathrm{j}, \mathrm{b}, \mathrm{e}), \text { provided } \text { pro }_{\mathrm{i}}<\text { u.o. }
\end{aligned}
$$

Informally, (23) says that there is an event of John driving to Bordeaux that is included within the past interval pro $_{i}$. Sentence (24) says that there is an event of John going to Bordeaux that includes the past interval pro $_{i}$.

As said at the beginning of this section, the framework presented in this section is nothing but a compositional implementation of the perspective-based approach and, as such, it fails to account for the imperfective paradox. Notice, in fact, that the truth-conditions in (24) entail the existence of an event of John driving to Bordeaux.

\subsection{The internal structure of telic predicates}

In this section, we put forward my proposal. As anticipated, the idea is that progressive/imperfective sentences do involve quantification over inertia worlds, as in the modal version of the event-based approach, but such modality is not introduced by the progressive operator; rather, it is a property of telic predicates themselves. This possibility has been explored by Bennett (1977), who proposes that verbs of creation are inherently intensional: ${ }^{9}$

My own view is that the fact that John is building a house has a reading that does not imply the existence of a house should be explained by analyzing build as an intensional verb. More precisely, I propose to analyze the performance verb phrase build a house as build something to be a house. This allows for a house to have narrow scope with respect to an intensional context, and this explains why John is building a house, on one reading, does not imply that there is, or will be, a house. . . . There are several verbs like build that allow for such non referential readings: draw, paint, compose, write, and make. Such verbs form a special class that I will call verbs of creation. (pp. 504-5)

Crucially, our proposal will differ from that of Bennett in that it will extend to all telic predicates. More precisely, we will propose that telic predicates create intensional contexts for the evaluation of the existence of an event representing the telos of the predicate.

Vendler (1967) classifies events in two broad classes: atelic events (such as events of running and sleeping) and telic events (such as events of driving to Amsterdam and building a house). Telic events have an inherent end/culmination point (i.e. a telos), whereas atelic predicates do not. Atelic predicates are characterized by the sub-interval property (Bennett and Partee, 1972) ${ }^{10}$ :

Sub-interval property

For any atelic predicate of events $\mathrm{P}$, event $\mathrm{e}$, and interval $\mathrm{i}$, if $\mathrm{P}(\mathrm{e})$ is true at $\mathrm{i}$ then, for any interval i', if $i^{\prime} \subseteq i, P(e)$ is also true at $i^{\prime}$

\footnotetext{
${ }^{9}$ We quote from Zucchi (1999, pp. 190-1).

${ }^{10}$ The definition in (25) is stated in the language of events whereas Bennett and Pertee's original definition is stated in terms of time intervals only.
} 
That is to say, atelic predicates denote events with homogeneous sub-parts; intuitively, every sub-part of an activity of running is in itself an activity of running.

The sub-interval property does not apply to telic predicates, since the internal constitution of the events denoted by such predicates is not homogeneous. For example, a subpart of an event of driving to Bordeaux is not in itself an event of driving to Bordeaux.

It has been proposed in several places (Dowty 1977; 1979; Higginbotham 2000; Moens and Steedman 1988; Pustejovsky 1991) that the events denoted by telic predicates can be analyzed as having a complex internal structure. According to this view, a telic predicate involves the coming about of a particular state of affairs. For instance, the bare predicate 'John drive to Bordeaux' can be regarded as introducing a relation between an activity, the activity of John driving ${ }^{11}$, and a state, the state of John being in Bordeaux, such that the latter state is brought about by the former activity. Following this insight, let us assume denotations for atelic and telic predicates similar to those in (26) and (27):

$$
\begin{aligned}
& {\left[\left[\left[{ }_{\text {vP }} \text { John run }\right]\right]\right]=\lambda \mathrm{e} . \operatorname{Run}(\mathrm{e}, \mathrm{j})} \\
& {\left[\left[\left[{ }_{\mathrm{vP}} \text { John drive to Bordeaux }\right]\right]\right]=\lambda \mathrm{e} . \operatorname{Drive}(\mathrm{e}, \mathrm{j}) \wedge \exists \mathrm{e}^{\prime} . \operatorname{Be}\left(\mathrm{e}^{\prime}, \mathrm{j}, \mathrm{b}\right) \wedge \operatorname{Telos}\left(\mathrm{e}, \mathrm{e}^{\prime}\right)}
\end{aligned}
$$

According to (26), the atelic predicate John run denotes the set of events $e$ of John running; according to (27), the telic predicate John drive to Bordeaux denotes the set of events $e$ of John driving for which there is an event $e^{\prime}$ of John being in Bordeaux such that $e^{\prime}$ is the telos of $e$.

What is the nature of the relation Telos? Dowty (1977) reduces it to a set of more primitive predicates, such as Cause and Become; Moens and Steedman (1988) introduce the notion of 'contingency', a relation between events that is more complex than temporal sequentiality but different from causality. Be as it may, we are going to assume that whatever the Telos relation is, it is at least an asymmetric relation between two events that entails sequentiality. More precisely, for any two events $e$ and $e^{\prime}$, if $e^{\prime}$ is the telos of $e$, then $e$ immediately precedes $e^{\prime}$. That is:

$$
\text { For any two events } e \text { and } e^{\prime} \text {, if } \operatorname{Telos}\left(e, e^{\prime}\right) \text {, then } \tau(e)<_{\mathrm{I}} \tau\left(e^{\prime}\right)
$$

We can represent a telic event graphically as in Fig. 2, that is, as a sequence of (at least) two sub-events. In the case of the predicate John drive to Bordeaux, the first event corresponds to the activity of John driving, whereas the second event corresponds to the state of John being in Bordeaux.

Fig. 2

Event 1

Event 2

As anticipated, the core of our proposal is that telic predicates are inherently modal. The idea is that a telic predicate denotes a set of events that in every inertia world, i.e. in every possible world in which nothing interferes with them, reach a certain culmination. To see an example,

\footnotetext{
${ }^{11}$ To be precise, we should say that the first event is an event of John driving towards/in the direction of Bordeaux. To keep formulas short, I will simply refer to the first event as an event of John driving.
} 


\section{GAETANO FIORIN AND DENIS DELFITTO}

I propose that the predicate John drive to Bordeaux denotes the set of events $e$ of John driving such that, in every possible world in which nothing interferes with $e, e$ culminates in a state of John being in Bordeaux. More formally:

$$
\begin{aligned}
& {[[[\mathrm{vp} J o h n \text { drive to Bordeaux }]]]^{\mathrm{w}}=\lambda \mathrm{e} . \operatorname{Drive}(\mathrm{e}, \mathrm{j}) \wedge \forall \mathrm{w}^{\prime} \in \mathrm{I}(\mathrm{w}, \mathrm{M}, \mathrm{O}) . \exists \mathrm{e}^{\prime}} \\
& \operatorname{Be}\left(\mathrm{e}^{\prime}, \mathrm{j}, \mathrm{b}\right)\left(\mathrm{w}^{\prime}\right) \wedge \operatorname{Telos}\left(\mathrm{e}, \mathrm{e}^{\prime}\right)\left(\mathrm{w}^{\prime}\right)
\end{aligned}
$$

According to (29), [vp John drive to Bordeaux] denotes the set of events $e$ of John driving such that, in every world $w^{\prime}$ in which nothing interferes with John's driving, there is an event $e^{\prime}$ of John being in Bordeaux such that $e^{\prime}$ is the telos of $e$.

Notice, as Bennett does, that once such a perspective is endorsed the problem of the imperfective paradox is somewhat reversed. Whereas under a more traditional approach the question is why John was building a house does not entail the coming into existence of a house, under the present approach the question is why John built a house does entail the existence of a house:

However, John built a house last year should imply a house existed last year. But how does this follow if the former sentence is analyzed as John built something to be a house last year? We impose the condition that if John is in the extension of build something to be a house at a closed interval I, then something is in the extension of be a house at the final endpoint of I. (Bennett 1977, p. 508)

Our strategy follows Bennett's suggestion. In (29) we have defined inertia worlds on the basis of three parameters: a world of evaluation $w$, a modal base $M$, and an ordering source $O$. This is consistent with Portner (1998). We now propose a further refinement: inertia worlds are defined also on the basis of a temporal parameter corresponding to the reference time (this refinement of Portner's analysis of inertia worlds has been proposed for independent reasons by Ferreira 2005, p. 115). Accordingly, inertia worlds are those worlds in the modal base $M$, that are ranked as most similar to the world of evaluation $w$ according to the ordering source $O$, and which are identical to $w$ in the stretch of time that corresponds to the reference time $i$. As we will show in the next section, it is the presence of this temporal parameter that is responsible for the fact that PERF neutralizes the modality of telic predicates.

As a conclusion, the denotation we propose for a telic predicate such as ${ }_{v P} J o h n$ drive to Bordeaux] is exemplified in (30).

$$
\begin{aligned}
& \llbracket\left[\left[\mathrm{vp}^{\prime} \mathrm{John} \text { drive to Bordeaux] }\right]\right]^{\mathrm{w}}=\lambda \mathrm{e} . \lambda \mathrm{i} \text {. Drive }(\mathrm{e}, \mathrm{j}) \wedge \forall \mathrm{w}^{\prime} \in \mathrm{I}(\mathrm{w}, \mathrm{M}, \mathrm{O}, \mathrm{i}) . \exists \mathrm{e}^{\prime} \\
& \operatorname{Be}\left(\mathrm{e}^{\prime}, \mathrm{j}, \mathrm{b}\right)\left(\mathrm{w}^{\prime}\right) \wedge \operatorname{Telos}\left(\mathrm{e}, \mathrm{e}^{\prime}\right)\left(\mathrm{w}^{\prime}\right)
\end{aligned}
$$

According to (30), [vP John drive to Bordeaux] denotes a function from events $e$ into a function from intervals of time $i$ into truth-values such that $e$ is an event of John driving, and in every inertia world $w^{\prime}$ defined on the basis of $w, M, O$, and $i$, there is an event $e^{\prime}$ of John being in Bordeaux such that $e^{\prime}$ is the telos of $e$.

This is the core of our proposal: Telic predicates have a complex internal structure which entails a modal relation between two events and which is defined on the basis of a world parameter, a modal base, an ordering source, and a temporal parameter corresponding to the reference time.

\subsection{Accounting for the imperfective paradox}


Apart from the innovation introduced in the preceding section, we now wish to maintain our syntax and semantics of Tense and Aspect as close as possible to that presented in section 6.2.

There is, however, one important modification that needs to be made. In the framework presented in 6.2, vPs denote sets of events, i.e. their denotation is of type $<\mathrm{ev}, \mathrm{t}>$. Accordingly, aspectual operators were defined as functions from set of events into sets of intervals of time, type $<<\mathrm{ev}, \mathrm{t}\rangle,<\mathrm{i}, \mathrm{t}>>$. Notice that the denotation offered in (30) is of a different type, namely $\langle\mathrm{ev},<\mathrm{i}, \mathrm{t}>>$. This is because the temporal parameter $i$ is bound by a $\lambda$ operator. This is done to ensure that this parameter is identified with the reference time that is provided by the pronoun sitting in Tense.

Under these assumptions, the denotations of the PERF and PROG operators need to be modified in order for them to be compatible with the new semantic type of telic vPs. I propose the denotations in (31) and (32).

$$
\begin{aligned}
& {[[\mathrm{PERF}]]=\lambda \mathrm{P}_{<\mathrm{ev},<\mathrm{i}, t>>} . \lambda \mathrm{i} . \exists \mathrm{e} . \tau(\mathrm{e}) \subseteq \mathrm{i} \wedge \mathrm{P}(\mathrm{e})(\mathrm{i})} \\
& {[[\mathrm{PROG}]]=\lambda \mathrm{P}_{<\mathrm{ev},<\mathrm{i}, \mathrm{t}>>} . \lambda \mathrm{i} . \exists \mathrm{e} . \mathrm{i} \subseteq \tau(\mathrm{e}) \wedge \mathrm{P}(\mathrm{e})(\mathrm{i})}
\end{aligned}
$$

The operators in (31) and (32) are identical to those in (19) and (20) in that they map the denotation of the $\mathrm{vP}$ into a set of intervals. PERF maps the denotation of the $\mathrm{vP}$ into the set of intervals of time that include the event time. PROG maps the denotation of the vP into the set of intervals of time that are included within the event time. On the other hand, the operators in (31) and (32) differ from those in (19) and (20) in that they bind the temporal parameter that occurs in the denotation of telic predicates.

It is possible to show now that the present framework accounts for the following intuitions: (i) the progressive sentence in (33) does not entail that John reached Bordeaux; (ii) the simple-past sentence in (34) does entail that John reached Bordeaux.

John was driving to Bordeaux

John drove to Bordeaux

A derivation of the truth-conditions of (33), relatively to a world of evaluation $w$ and an utterance time $u$, is given in (35).

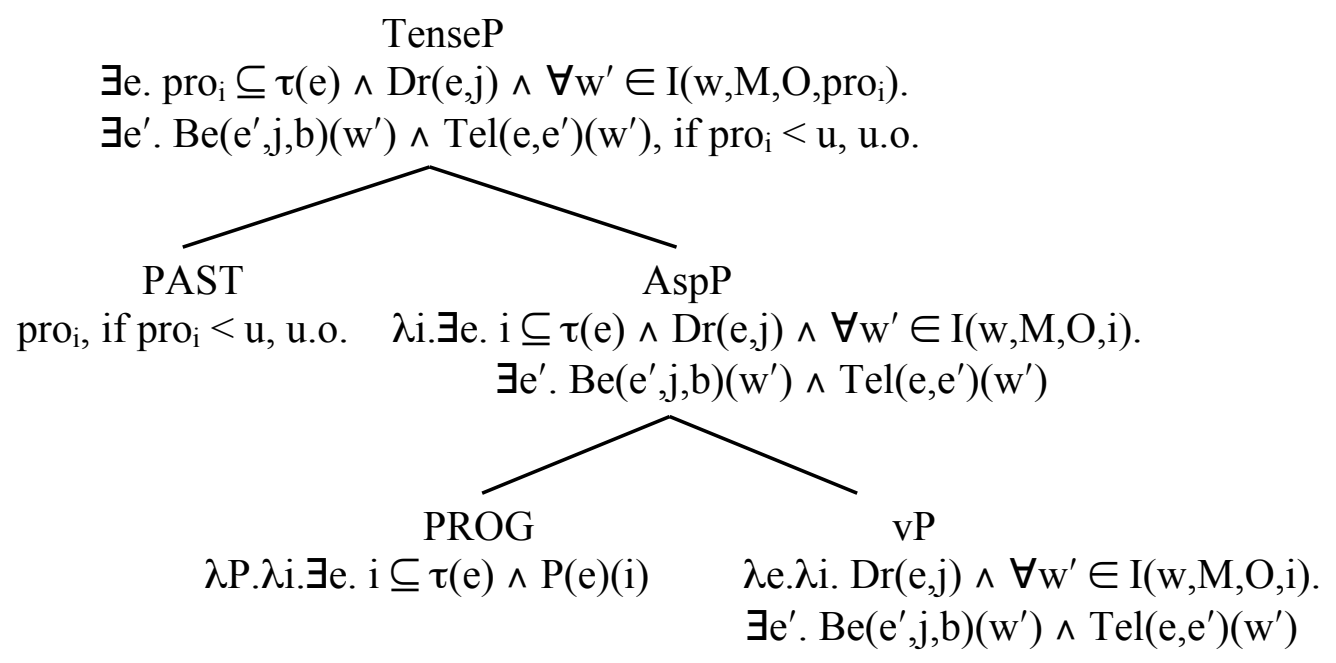




\section{GAETANO FIORIN AND DENIS DELFITTO}

According to (35), (33) is true iff there is an event $e$ of John driving such that its temporal extension includes the reference time pro $_{i}$ and, in every inertia world that is identical to $w$ in the stretch of time that corresponds to pro $_{i}$, there is an event of being in Bordeaux that is the telos of $e$ (provided pro $_{i}$ precedes the utterance time).

These truth-conditions do not entail that an event of John being in Bordeaux took place in the actual world, as the actual world need not be an inertia world. To see this consider the two scenarios depicted in Figures $3 \mathrm{a}$ and $3 \mathrm{~b}$, where $w_{@}$ is the world of evaluation and $w_{I}$ is the only inertia world accessible from $w_{@}$ that is identical to $w_{@}$ with respect to pro $_{i}$. The difference between Fig. 3a and Fig. 3b is that in Fig. 3a the event $e$ reaches its culmination $e^{\prime}$ both in $w_{I}$ and $w_{@}$, whereas in Fig. $3 \mathrm{~b} e$ reaches its telos only in $w_{I}$. Importantly, the truthconditions in (35) are verified by both scenarios, because in both scenarios $e$ reaches its culmination in all inertia worlds.

Fig. 3a



Fig. $3 b$

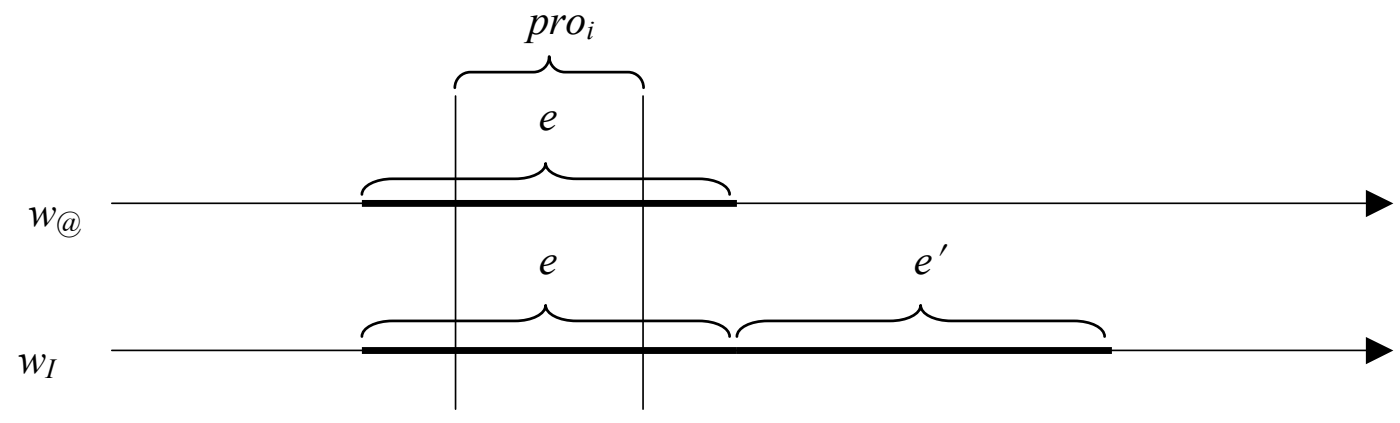

Consider now the case of the simple past sentence (34). The truth-conditions of (34) differ only in the relation between the event time and the reference time:

$$
[[(34)]]^{\mathrm{w}, \mathrm{u}}=\exists \text { e. } \tau(\mathrm{e}) \subseteq \operatorname{pro}_{\mathrm{i}} \wedge \operatorname{Dr}(\mathrm{e}, \mathrm{j}) \wedge \forall \mathrm{w}^{\prime} \in \mathrm{I}\left(\mathrm{w}, \mathrm{M}, \mathrm{O}, \operatorname{pro}_{\mathrm{i}}\right) . \exists \mathrm{e}^{\prime} . \quad \operatorname{Be}\left(\mathrm{e}^{\prime}, \mathrm{j}, \mathrm{b}\right)\left(\mathrm{w}^{\prime}\right)
$$
$\operatorname{Tel}\left(\mathrm{e}, \mathrm{e}^{\prime}\right)\left(\mathrm{w}^{\prime}\right)$, if $\operatorname{pro}_{\mathrm{i}}<\mathrm{u}$, u.o.

According to (36), (34) is true, relatively to a world of evaluation $w$ and an utterance time $u$, iff there is an event $e$ of John driving such that its temporal extension is included within the reference time pro $_{i}$ and, in every inertia world that is identical to $w$ in the stretch of time that corresponds to pro $_{i}$, there is an event of being in Bordeaux that is the telos of $e$ (provided pro $i$ precedes the utterance time).

There is one issue that we must clarify before proceeding. Notice that the truthconditions stated in (36) are compatible with a situation in which the temporal extension of the event of John driving includes the reference time. The reason is that the event of John 
driving is an atelic event and, given the sub-interval property (25), any of its sub-parts also counts as an event of John driving. Therefore, even in the case in which the actual event of John driving spans over the reference time, there still is a sub-part of it that is an event of John driving and is included within the reference time.

If this were the case, however, the semantic contribution of the PERF operator would be vacuous. We therefore assume that the temporal restriction imposed by PERF must be satisfied in a non-trivial way: the relevant event $e$ must be temporally included within the reference time and there must be no event $e^{\prime}$ such that $e$ is a subpart of $e^{\prime}$. Even though we will not make this further constraint explicit in the formulas, we ask the reader to keep it in mind nevertheless.

It is now possible to see that the truth-conditions in (36) entail that an event of John being in Bordeaux took place in the actual world. More precisely, these truth-conditions demand that the world of evaluation is itself an inertia world. To see this, consider the two scenarios in figures $4 \mathrm{a}$ and $4 \mathrm{~b}$. The truth-conditions are verified by the scenario in figure $4 \mathrm{a}$ : (i) $e$ is included in pro $_{i}$; (ii) $e$ culminates in an event $e^{\prime}$ in all inertia worlds $w_{I}$; (iii) $w_{I}$ is identical to $w_{@}$ in the stretch of time corresponding to pro $_{i}$. On the other hand, the same truthconditions are not verified by the scenario in figure $4 \mathrm{~b}$, that is, by a scenario in which $e$ did not reach its telos in the world of evaluation. The reason is that the condition that $w_{I}$ is identical to $w_{@}$ in the stretch of time corresponding to pro $_{i}$ is not met. In fact, in the stratch of time that corresponds to pro $_{i}, w_{@}$ hosts only the event $e$ whereas $w_{I}$ hosts both event $e$ and the first part of event $e^{\prime}$. The two words, inertia word and word of evaluation are therefore not identical. Therefore, the only case in which the identity condition between inertia worlds and world of evaluation is met is when the world of evaluation is also an inertia worlds. This derives the intuition that (34) entails that John arrived in Bordeaux.

Fig. $4 \mathrm{a}$

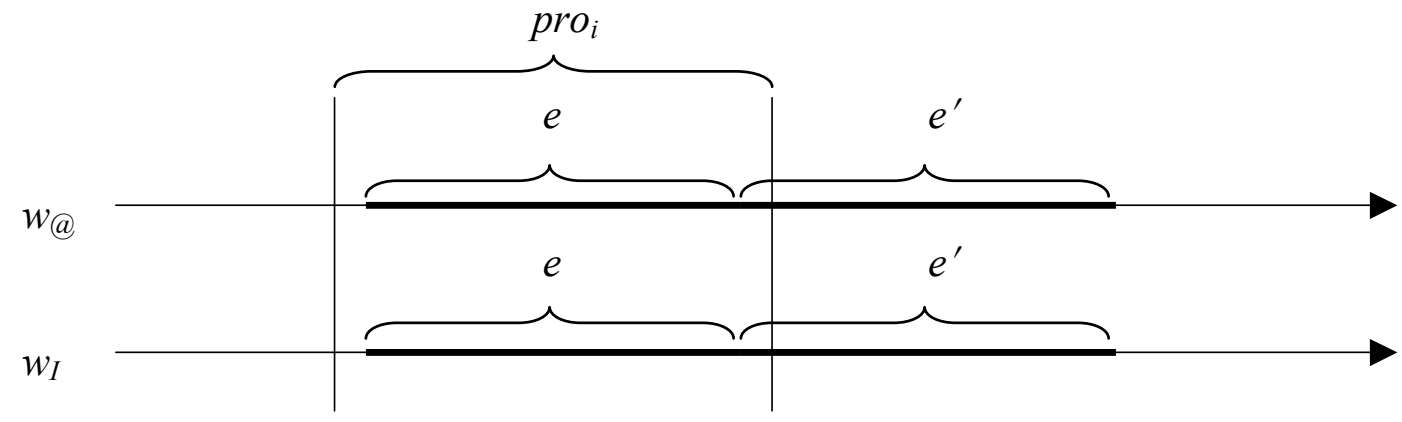

Fig. $4 b$

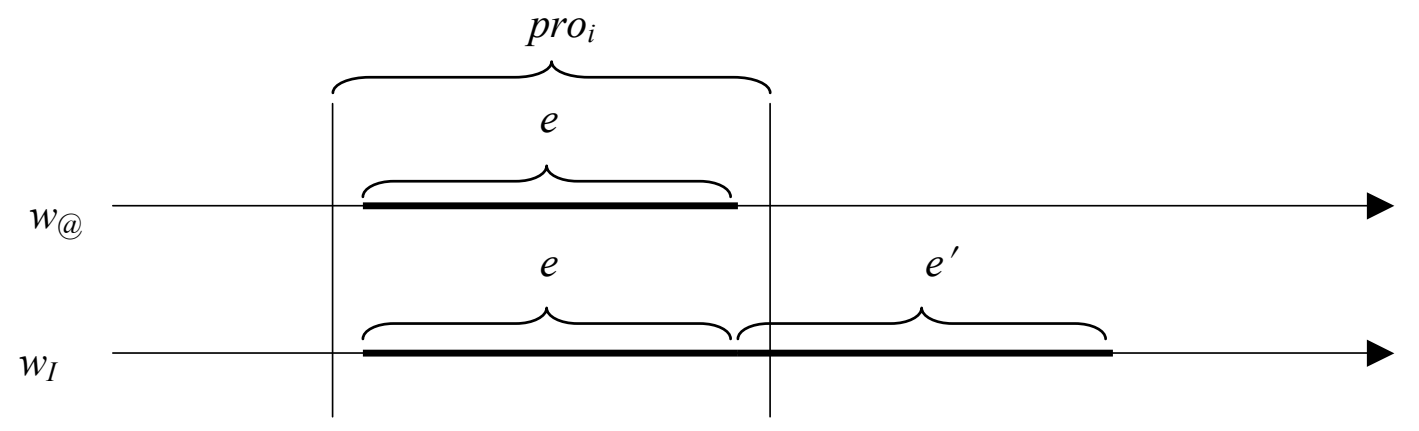

\subsection{Atelic predicates}




\section{GAETANO FIORIN AND DENIS DELFITTO}

In this section, we address a technical problem that arises from the proposal in the preceding section. In 6.4, we have proposed that the aspectual operator PROG and PERF are of type $<<\mathrm{ev},<\mathrm{i}, \mathrm{t}>>,<\mathrm{i}, \mathrm{t}>>$. This choice was motivated by the fact that in 6.3 we proposed that telic predicates are of type $<\mathrm{ev},<\mathrm{i}, \mathrm{t}>>$. What about atelic predicates? In (26), repeated below as (37), we have maintained that atelic predicates denote sets of events.

$$
[[[\mathrm{vP} \text { John run }]]]=\lambda \mathrm{e} . \operatorname{Run}(\mathrm{e}, \mathrm{j})
$$

The denotation in (37) is of type <ev,t> and, therefore, incompatible with the semantics type of the PROG and PERF operators proposed in 6.4.

We can think of three different solutions to this problem. The first solution is to assume distinct operators specifically devoted to telic and atelic predicates:

$$
\begin{array}{ll}
\text { a. } & {\left[\left[\mathrm{PERF}_{\text {Atelic }}\right]\right]=\lambda \mathrm{P}_{<\mathrm{i}, t>} . \lambda \mathrm{i} . \exists \mathrm{e} . \tau(\mathrm{e}) \subseteq \mathrm{i} \wedge \mathrm{P}(\mathrm{e})} \\
\text { b. } & {\left[\left[\mathrm{PROG}_{\text {Atelic }}\right]\right]=\lambda \mathrm{P}_{<\mathrm{i}, \mathrm{t}}>\lambda \mathrm{i} . \exists \mathrm{e} . \mathrm{i} \subseteq \tau(\mathrm{e}) \wedge \mathrm{P}(\mathrm{e})} \\
\text { a. } & {\left[\left[\mathrm{PERF}_{\text {Telic }}\right]\right]=\lambda \mathrm{P}_{<\mathrm{ev},<\mathrm{i}, \mathrm{t}>>} . \lambda \mathrm{i} . \exists \mathrm{e} . \tau(\mathrm{e}) \subseteq \mathrm{i} \wedge \mathrm{P}(\mathrm{e})(\mathrm{i})} \\
\text { b. } & {\left[\left[\mathrm{PROG}_{\text {Telic }}\right]\right]=\lambda \mathrm{P}_{<\mathrm{ev},<\mathrm{i}, \mathrm{t}>} . \lambda \mathrm{i} . \exists \mathrm{i} \subseteq \tau(\mathrm{e}) \wedge \mathrm{P}(\mathrm{e})(\mathrm{i})}
\end{array}
$$

The operators in (38) are used when the vP denotes an atelic event, whereas the operators in (39) are used when the vP denotes a telic event.

A second solution is to assume that atelic predicates have denotations such as the one exemplified in (40), with a vacuous $\lambda$-operator over interval of times. This would make the denotation of atelic events of the correct type without affecting their content.

$$
\left[\left[\left[{ }_{\text {vP }} \text { John run }\right]\right]\right]=\lambda \mathrm{e} . \lambda \mathrm{i} . \operatorname{Run}(\mathrm{e}, \mathrm{j})
$$

A third possibility is to give atelic predicates the same denotation as telic predicates. This is exemplified in (41). Under this option, atelic predicates denote a relation between two events in the same way as telic predicates do. The crucial difference is that, in the case of atelic predicates, the two events are identical. For example, the predicate [vP John run] denotes a relation between two events of John running.

$$
\begin{aligned}
& \llbracket[\text { [vp John run] }]]^{\mathrm{w}}=\lambda \mathrm{e} . \lambda \mathrm{i} . \operatorname{Run}(\mathrm{e}, \mathrm{j}) \wedge \forall \mathrm{w}^{\prime} \in \mathrm{I}(\mathrm{w}, \mathrm{M}, \mathrm{O}, \mathrm{i}) . \exists \mathrm{e}^{\prime} . \operatorname{Run}\left(\mathrm{e}^{\prime}, \mathrm{j}\right)\left(\mathrm{w}^{\prime}\right) \wedge \\
& \operatorname{Telos}\left(\mathrm{e}, \mathrm{e}^{\prime}\right)\left(\mathrm{w}^{\prime}\right)
\end{aligned}
$$

At this point, we do not see empirical reasons for preferring one option to the others, as they all predict correct truth-conditions.

\subsection{Accounting for KP's findings}

The present theory qualifies as a perspective-based theory in that it maintains that the role of the imperfective/progressive is to present an eventuality from an internal perspective. As such it can be used to explain the children's difficulty in associating an imperfective sentence with an incomplete event when a reference time is not provided explicitly.

The idea we wish to pursue is that, when children are not provided with an explicit reference time, they simply take the past as the reference time. This hypothesis is formulated by KP: 'We suggest that in the absence of an explicit temporal modifier or other strongly biasing context, Russian children instead evaluate imperfectives using a default perspective interval that spans the entire event, and possibly continues to the present. Such a wide 
perspective includes the event failure and would therefore prevent children from projecting a hypothetical continuation of the event to completion that diverges from the actual world only after the perspective interval' (KP, p. 93).

The present framework allows implementing this hypothesis in a straightforward way. As we saw, telic predicates entail their culmination only in the case in which the reference time includes the event time. This is what happens with perfective sentences: The external perspective has the effect of neutralizing the modality of telic predicates. The reason is that inertia worlds must be identical to the actual world in the portion of time that corresponds to the reference time. This requirement forces the actual world to be itself an inertia world for the sentence to be true.

Suppose, as KP propose, that children, when left without a readily accessible temporal perspective, evaluate imperfective sentences using a default perspective corresponding to the past, that is, the whole time span preceding the utterance time. The use of this default perspective would have the undesired consequence of requiring that all inertia worlds are identical to the actual world for a span of time larger than the event itself and, therefore, would force the actual world to be itself an inertia world, that is, a world in which the event reaches its culmination.

\section{A FURTher EXTENSION OF THE PROPOSAL: Two Classes OF Ditransitive VERBS}

There is another, related class of data that can be accounted for within the present framework. The relevant observation concerns the contrast between ditransitive verbs such as give and hand and ditransitive verbs such as send and throw. In the simple past, a verb such as give entails that the thing that is given has reached the goal of the giving; sentence (42a), for example, entails that the letter has reached Mary. On the other, a verb such as send, again in the simple past, does not entail that the thing that is sent has reached the goal of the sending; sentence (42b) does not entail that the letter has reached Mary. A similar contrast is reported in (43); whereas (43a) entails that John has received the ball, (43b) does not license the same entailment.

(42) a. John gave the letter to Mary

b. John sent the letter to Mary
a. Mary handed the ball to John
b. Mary threw the ball to John

These facts have been reported and discussed by Jackendhoff (1990), Koening and Davis (2001), Oehrle (1976), and Rappaport Hovav and Levin (2008).

The present framework allows accounting for the contrast in (42) if the predicates $x$ give $z$ to $y$ and $x$ send $z$ to $y$ are given denotations of the following type:

[[ $\left.\left[\begin{array}{llllll}\mathrm{vP} & x & \text { give } & z & \text { to } & y]\end{array}\right]\right]^{\mathrm{w}}=\lambda \mathrm{e}^{\prime} . \lambda \mathrm{i} . \exists \mathrm{e} . \operatorname{Be}(\mathrm{e}, \mathrm{x}, \mathrm{z}) \wedge \quad \forall \mathrm{w}^{\prime} \in \mathrm{I}(\mathrm{w}, \mathrm{M}, \mathrm{O}, \mathrm{i})$. $\operatorname{Moves}\left(\mathrm{e}^{\prime}, \mathrm{z}, \mathrm{x}, \mathrm{y}\right)\left(\mathrm{w}^{\prime}\right) \wedge \operatorname{Telos}\left(\mathrm{e}, \mathrm{e}^{\prime}\right)\left(\mathrm{w}^{\prime}\right) \wedge \forall \mathrm{w}^{\prime \prime} \in \mathrm{I}(\mathrm{w}, \mathrm{M}, \mathrm{O}, \mathrm{i}) . \exists \mathrm{e}^{\prime \prime} . \quad \operatorname{Be}\left(\mathrm{e}^{\prime \prime}, \mathrm{y}, \mathrm{z}\right)\left(\mathrm{w}^{\prime}\right) \wedge$ $\operatorname{Telos}\left(\mathrm{e}^{\prime}, \mathrm{e}^{\prime \prime}\right)\left(\mathrm{w}^{\prime}\right)$

[[ $\left[{ }_{\mathrm{vp}} \quad x\right.$ send $z$ to $\left.\left.\left.y\right]\right]\right]^{\mathrm{w}}=\lambda \mathrm{e} . \lambda \mathrm{i} . \operatorname{Be}(\mathrm{e}, \mathrm{x}, \mathrm{z}) \wedge \forall \mathrm{w}^{\prime} \in \mathrm{I}(\mathrm{w}, \mathrm{M}, \mathrm{O}, \mathrm{i}) . \quad \exists \mathrm{e}^{\prime}$. $\operatorname{Moves}\left(\mathrm{e}^{\prime}, \mathrm{z}, \mathrm{x}, \mathrm{y}\right)\left(\mathrm{w}^{\prime}\right) \wedge \operatorname{Telos}\left(\mathrm{e}, \mathrm{e}^{\prime}\right)\left(\mathrm{w}^{\prime}\right) \wedge \forall \mathrm{w}^{\prime \prime} \in \mathrm{I}(\mathrm{w}, \mathrm{M}, \mathrm{O}, \mathrm{i}) . \exists \mathrm{e}^{\prime \prime} . \quad \operatorname{Be}\left(\mathrm{e}^{\prime \prime}, \mathrm{y}, \mathrm{z}\right)\left(\mathrm{w}^{\prime}\right) \wedge$ $\operatorname{Telos}\left(\mathrm{e}^{\prime}, \mathrm{e}^{\prime \prime}\right)\left(\mathrm{w}^{\prime}\right)$ 


\section{GAETANO FIORIN AND DENIS DELFITTO}

According to (44) and (45) both predicates denote sets of events that are part of a sequence of three events: an event of $z$ being at $x$ 's location (or in $x$ 's possession); an event of $z$ moving from $x$ towards $y$; an event of $z$ being at $y$ 's location (or in $y$ 's possession). (44) and (45) differs in which of the three events in the sequence corresponds to the denotation of the predicate. In the case of give, it is the second event in the sequence that corresponds to the denotation of the predicate. In the case of send, it is the first event in the sequence that corresponds to the denotation of the predicate. In other words, the predicate $x$ give $z$ to $y$ denotes a set of events of $z$ moving from $x$ towards $y$ that is the telos of an event of $x$ having $z$ and whose telos is an event of $y$ having $z$. The predicate $x$ send $z$ to $y$ denotes a set of events of $x$ having $z$, whose telos is an event of $z$ moving from $x$ towards $y$, whose telos, in turn, is an event of $y$ having $z$.

The denotations in (44) and (45), together with denotations for PERF and PAST proposed in section 6 , provide the truth-conditions in (46) and $(47)^{12}$ for the sentence (42a) and $(42 b)$.

$$
\begin{aligned}
& \text { [[ (42a) ] }]^{\mathrm{w}}=\exists \mathrm{e}^{\prime} . \tau\left(\mathrm{e}^{\prime}\right) \subseteq \operatorname{pro}_{\mathrm{i}} \wedge \exists \mathrm{e} . \operatorname{Be}(\mathrm{e}, \mathrm{j}, \mathrm{l}) \wedge \forall \mathrm{w}^{\prime} \in \mathrm{I}\left(\mathrm{w}, \mathrm{M}, \mathrm{O}, \operatorname{pro}_{\mathrm{i}}\right) . \\
& \operatorname{Moves}\left(\mathrm{e}^{\prime}, 1, \mathrm{j}, \mathrm{m}\right)\left(\mathrm{w}^{\prime}\right) \wedge \operatorname{Telos}\left(\mathrm{e}, \mathrm{e}^{\prime}\right)\left(\mathrm{w}^{\prime}\right) \wedge \quad \forall \mathrm{w}^{\prime \prime} \in \mathrm{I}\left(\mathrm{w}, \mathrm{M}, \mathrm{O}, \mathrm{pro}_{\mathrm{i}}\right) . \quad \exists \mathrm{e}^{\prime \prime} . \\
& \operatorname{Be}\left(\mathrm{e}^{\prime \prime}, \mathrm{m}, \mathrm{l}\right)\left(\mathrm{w}^{\prime}\right) \wedge \operatorname{Telos}\left(\mathrm{e}^{\prime}, \mathrm{e}^{\prime \prime}\right)\left(\mathrm{w}^{\prime}\right) \\
& {\left[[(42 b)]^{\mathrm{w}}=\exists \mathrm{e} . \tau\left(\mathrm{e}^{\prime}\right) \subseteq \operatorname{pro}_{\mathrm{i}} \wedge \operatorname{Be}(\mathrm{e}, \mathrm{j}, \mathrm{l}) \wedge \forall \mathrm{w}^{\prime} \in \mathrm{I}\left(\mathrm{w}, \mathrm{M}, \mathrm{O}, \operatorname{pro}_{\mathrm{i}}\right) . \quad \exists \mathrm{e}^{\prime} .\right.} \\
& \operatorname{Moves}\left(\mathrm{e}^{\prime}, \mathrm{b}, \mathrm{j}, \mathrm{m}\right)\left(\mathrm{w}^{\prime}\right) \wedge \operatorname{Telos}\left(\mathrm{e}, \mathrm{e}^{\prime}\right)\left(\mathrm{w}^{\prime}\right) \wedge \quad \forall \mathrm{w}^{\prime \prime} \in \mathrm{I}\left(\mathrm{w}, \mathrm{M}, \mathrm{O}, \mathrm{pro}_{\mathrm{i}}\right) . \quad \exists \mathrm{e}^{\prime \prime} . \\
& \operatorname{Be}\left(\mathrm{e}^{\prime \prime}, \mathrm{m}, \mathrm{b}\right)\left(\mathrm{w}^{\prime}\right) \wedge \operatorname{Telos}\left(\mathrm{e}^{\prime}, \mathrm{e}^{\prime \prime}\right)\left(\mathrm{w}^{\prime}\right)
\end{aligned}
$$

The truth-conditions in (46) and (47) correctly capture the fact that (42a) entails that the letter reached Mary, whereas (42b) does entail that the letter reached Mary. To see why, it is useful to look at the graphic renderings in figures 5 and 6 . Consider first sentence (42a), along with figures $5 \mathrm{a}$ and $5 \mathrm{~b}$. The truth-conditions in (46) require that the second event in the sequence, i.e. $e^{\prime}$, is included within the reference time pro $_{i}$ and that $e^{\prime}$ reaches its telos $e^{\prime \prime}$ in all inertia worls $w_{I}$ accessible from the actual world $w_{@}$ which are identical to $w_{I}$ in the stretch of time that corresponds to $w_{I}$. These truth-conditions are verified by a situation such as the one in figure $5 \mathrm{a}$, but not in the situation depicted in figure $5 \mathrm{~b}$, because in figure $5 \mathrm{~b}$ the inertia world $w_{I}$ is not identical to the actual world $w_{@}$ in the stretch of time that corresponds to the reference time. This result is identical to that obtained in section 6 for other simple past sentences. The requirement that the accessible inertia worlds must be identical to the actual world in the portion of time corresponding to the reference time has the effect of neutralizing the inherent modality of telic predicates.

Fig. 5a

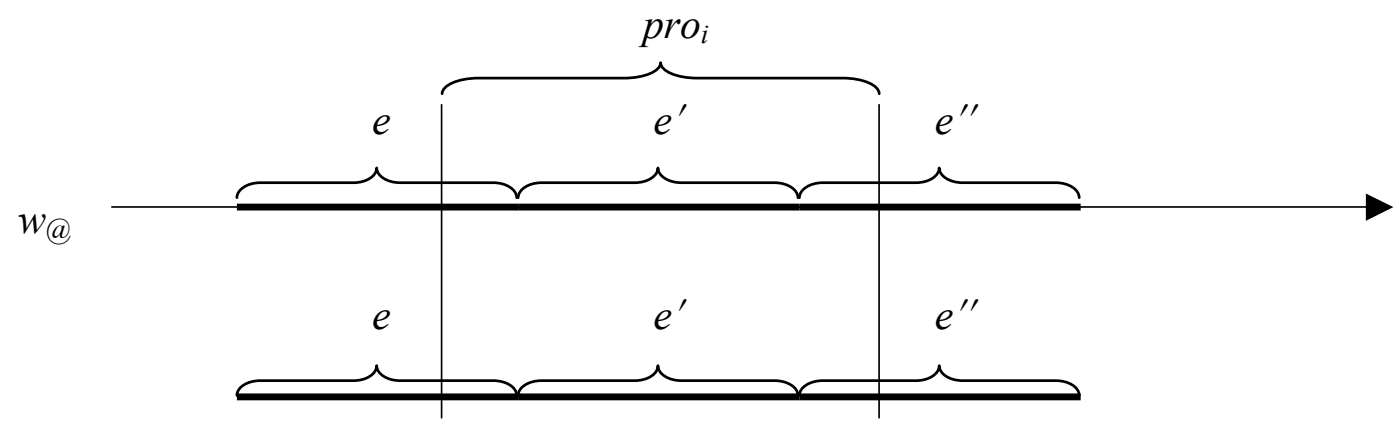

\footnotetext{
${ }^{12}$ For simplicity, in the truth-conditions in (46) and (47) I am translating the definite description the letter into the constant $l$, instead of using the iota term $\iota x$. Letter $(x)$.
} 
$w_{I}$

Fig. $5 b$

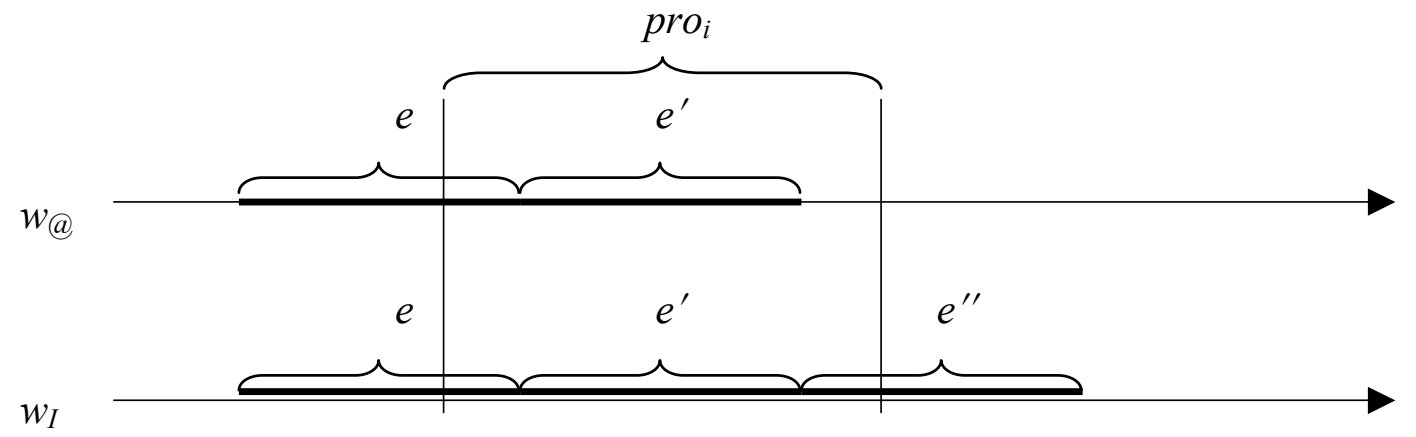

Consider now sentence (42b), along with figures $6 a$ and $6 \mathrm{~b}$. The truth-conditions in (47) require that the first event in the sequence, i.e. $e$, is included within the reference time pro $_{i}$ and that $e$ reaches its telos $e^{\prime}$ in all inertia worls $w_{I}$ accessible from the actual world $w_{0}$ which are identical to $w_{I}$ in the stretch of time that corresponds to $w_{I}$. These truth-conditions are verified both by the situation depicted in figure $6 \mathrm{a}$ and by the situation depicted in figure $6 \mathrm{~b}$. In fact, in both situations the first event in the sequence, i.e. $e$, reaches its telos $e^{\prime}$ in every inertia world accessible from the actual world; moreover, both situation satisfy the requirement that the accessible inertia worlds are identical to the actual world in the portion of time corresponding to the reference time. The fact that the sentence is true in a situation such as the one depicted in figure $6 \mathrm{~b}$, indicates that the sentence can be true even when $e^{\prime \prime}$, the event of Mary being in possession of the letter, is not realized in the actual world. This means that the sentence can be true even in a scenario in which the letter has not reached Mary.

Fig. 6a



Fig. $6 b$

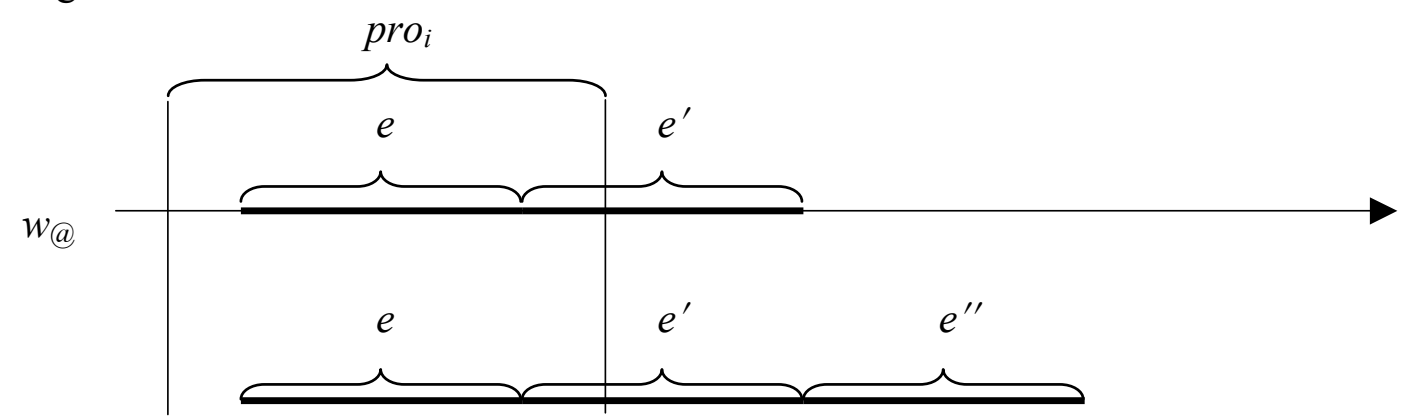


$w_{I}$

\section{CONCLUSIONS}

In this article, we defended a perspective-based approach to the progressive. The attempt was motivated by the experimental findings on language acquisition reported by KP. The theory we defended maintains that the role of the progressive is to encode an inner temporal perspective towards the event denoted by the bare predicate. To account for the fact that progressive sentences, when applied to telic predicates, do not entail the culmination of the relevant event, we have proposed, developing and extending a suggestion by Bennett (1977), that telic events have a complex internal structure entailing a modal relation between two subevents. To account for the fact that simple past sentences, when applied to telic predicates, entail the culmination of the relevant event, we have proposed that the modal relation between events encoded by telic predicates is evaluated relatively to a temporal parameter corresponding to the reference time. We have finally shown that the theory offers an account of the experimental findings of KP and we have extended the proposal to account for the different entailment properties of two classes of ditransitive verbs.

\section{REFERENCES}

Asher, Nicholas. 1992. A default truth conditional semantics for the progressive. Linguistics and Philosophy 15, 463-508.

Bach, E. 1986. The Algebra of Events. Linguistics and Philosophy 9, 5-16.

Bennett, M. 1977. A Guide to the Logic of Tense and Aspect in English. Logique et Analyse 20, 491-517.

Bennett, M. and B.H. Partee 1972. Toward the logic of tense and aspect in English. System Development Corporation, Santa Monica, Calif. Reprinted in Partee, B. Compositionality in Formal Semantics (2004). Oxford: Blackwell.

Delfitto, D. 2002. Genericity in language: Issues of syntax, logical form and interpretation. Alessandria: Edizioni Dell'Orso,

Delfitto, D. 2004. On the logical form of imperfective aspect. In J. Guéron and J. Lecarme (eds.), The syntax of Tense, Cambridge, MA: MIT Press, 115-142.

Dowty, D.R. 1972. Studies in the Logic of Verb Aspect and Time Reference in English (Studies in Linguistics). Department of Linguistics, University of Texas, Austin.

Dowty, D.R. 1977. Toward a semantic analysis of verb aspect and the English imperfective paradox. Linguistics and Philosophy, 1, 45-78.

Dowty, D.R. 1979. Word Meaning and Montague Grammar. Boston: Reidel.

Ferreira, M. 2005. Event quantification and plurality. PhD dissertation, MIT, Cambridge, MA.

Higginbotham, J. 2000. Accomplishments. Ms. USC and University of Oxford.

Jackendoff, R.S. (1990). Semantic structures. Cambridge, MA: MIT Press.

Kamp, H., and U. Reyle 1993. From discourse to logic. Dordrecht: Kluwer.

Kazanina, N. and C. Phillips 2007. A developmental perspective on the imperfective paradox. Cognition, 105, 65-102.

Klein, W. 1994. Time in language. London: Routledge.

Klein, W. 1995. A time relational analysis of Russian aspect. Language, 68, 525-52.

Koenig, J.-P. \& A.R. Davis 2001. Sublexical modality and the structure of lexical semantic representations. Linguistics and Philosophy, 24, 71-124. 
Kratzer, A. 1991. Modality. In Semantics: An International Handbook of Contemporary Research, ed. A. von Stechow and D. Wunderlich, 639-50. Berlin: de Gruyter.

Krifka, M. 1988. Some linguistic devices for event quantization and event measurement. Presented at Conference on Events and Natural Language Metaphysics, Center for Cognitive Studies, University of Texas at Austin.

Landman, F. 1992. The progressive. Natural Language Semantics, 1, 1-32.

Moens, M. and M. Steedman. 1988. Temporal ontology and temporal reference. Computational Linguistics, 14, 15-28.

Oehrle, R.T. 1976. The grammatical status of the English dative alternation. Ph.D. dissertation, MIT, Cambridge, MA.

Parsons, T. 1990. Events in the Semantics of English: A Study in Subatomic Semantics. Cambridge, MA: MIT Press.

Partee, B.H. 1973. Some structural analogies between tenses and pronouns in English. The Journal of Philosophy 70, 601-609.

Portner, P. 1998. The progressive in modal semantics. Language, 74, 760-87.

Pustejovsky, J. 1991. The syntax of event structure. Cognition 41, 47-81.

Ramchand, Gillian. 2004. Time and the event: The semantics of Russian prefixes. Norlyd, 32 , 323-61.

Rappaport Hovav, M. and B. Levin 2008. The English Dative alternation: The case for verb sensitivity. Journal of Linguistics 44, 129-116.

Reichenbach, H. 1947. Elements of Symbolic Logic. New York: The Free Press.

Smith, C. 1991. The Parameter of Aspect. Dordrecht: Kluwer.

Vendler, Z. 1967. Verbs and times. In Z. Vendler, Linguistics in Philosophy, Ithaca, NY: Cornell University Press, 97-121.

Wagner, L. 2001. Aspectual influences on early tense comprehension. Journal of Child Language, 28, 661-81.

Zucchi, S. 1999. Incomplete events, intensionality and imperfective aspect. Natural Language Semantics, 7, 179-215. 